BULLETIN Bulletin hispanique

HispaniQuE Université Michel de Montaigne Bordeaux

114-1 | 2012

Varia

\title{
Verso y reverso
}

teoría pragmática de la ironía y el humor en la poesía española contemporánea

Susana Rodríguez Rosique y Luis Bagué Quílez

\section{(2) OpenEdition}

Journals

Edición electrónica

URL: http://journals.openedition.org/bulletinhispanique/1925

DOI: 10.4000/bulletinhispanique.1925

ISSN: 1775-3821

Editor

Presses universitaires de Bordeaux

Edición impresa

Fecha de publicación: 1 junio 2012

Paginación: 411-438

ISBN: 978-2-86781-812-7

ISSN: 0007-4640

Referencia electrónica

Susana Rodríguez Rosique y Luis Bagué Quílez, «Verso y reverso », Bulletin hispanique [En línea], 114-1 | 2012, Publicado el 01 junio 2015, consultado el 30 abril 2019. URL : http://

journals.openedition.org/bulletinhispanique/1925; DOI : 10.4000/bulletinhispanique.1925

Tous droits réservés 


\title{
Verso y reverso: teoría pragmática de la ironía y el humor en la poesía española contemporánea
}

\author{
Susana Rodríguez Rosique \\ LUIS BAGUÉ QuílEz \\ Universidad de Alicante ${ }^{1}$
}

Cet article aborde, d'un point de vue pragmatique, les relations entre l'ironie et l'humour. Les deux phénomènes sont conçus comme fondés sur le mécanisme du contraste : lìronie est liée au contraste inclusif, l'humour au contraste exclusif. Cette proposition peut être appliquée à la poésie espagnole des dernières décades du XX ${ }^{\circ}$ siècle en ce quelle se fonde sur un type de discours qui reflète le relativisme contemporain et qui recherche de nouvelles stratégies de complicité avec son destinataire.

Este articulo aborda las relaciones entre ironia y humor desde una perspectiva pragmática. Ambos fenómenos se conciben como mecanismos contrastivos: mientras que la ironia se vincula con el contraste incluyente, el humor se asocia con el contraste excluyente. Esta propuesta se puede aplicar a la poesia española de las últimas décadas, basada en un tipo de discurso que refleja el relativismo contemporáneo y que busca nuevas estrategias de complicidad con el destinatario.

This paper deals, from a pragmatic point of view, with the relationship between irony and humour. Both phenomena are defined as founded upon contrastive mechanisms: whereas the former is related to inclusive contrast, the latter is linked to exclusive contrast. This proposal may be useful to study the Spanish poetry in the last decades of the twentieth century, which is based on a discourse reflecting contemporary relativism and asking for the addressee's complicity.

Mots-clefs : ironie, humour, contraste, poésie espagnole contemporaine.

1. Este trabajo se enmarca en el Proyecto de Investigación FFI2008-00179, «Aplicaciones a la clase de español como lengua extranjera de la ironía y el humor», concedido al grupo GRIALE por el Ministerio de Ciencia e Innovación. Asimismo, se incluye dentro del Programa Juan de la Cierva JCI-2009-04019 y del Proyecto de Investigación Emergente «El Humanismo europeo hacia el tercer milenio: comparatismo, interdisciplinariedad y perspectivas estéticas» (GRE0903) de la Universidad de Alicante. 


\section{I. - INTRODUCCIÓN: LAS RELACIONES PELIGROSAS}

La ironía y el humor son dos fenómenos que han ido adquiriendo una particular relevancia en los estudios pragmáticos de las últimas décadas. Esta atención puede explicarse por el tipo de significado que transmiten y por la amplitud de efectos comunicativos que generan. En los trabajos dedicados al tema, suele plantearse bien la posibilidad de diferenciar dos categorías o bien la voluntad de establecer un único ámbito de estudio. El propósito de este artículo es la descripción de ambos fenómenos desde el punto de vista de su significado. En este sentido, se ofrecen definiciones específicas: mientras que la ironía se relaciona con la negación, el humor se corresponde con la sustitución. Al mismo tiempo, los dos procedimientos se sitúan como extremos de un mismo continuo: el contraste.

Para llevar a cabo este análisis se ha seleccionado un corpus poético, lo que no suele ser frecuente en los enfoques pragmáticos sobre la ironía y el humor. Si bien los efectos de estos fenómenos se han observado en distintos tipos de interacción comunicativa, rara vez se han vinculado con su potencial estético. Es más, no siempre se ha contemplado la poesía como un cauce adecuado para el empleo de dichos mecanismos, excepto en algunos géneros como el epigrama o la sátira burlesca.

El Romanticismo concibió la ironía como lugar de intersección entre la Estética y la Poética, pues permitía incrementar la autoconciencia del autor y reivindicar la libertad creativa como superación de las contradicciones inherentes a la actividad artística. Sin embargo, en la tradición crítica contemporánea, a menudo se ha proclamado cierta incompatibilidad entre la disimulación que exige la ironía y la inmediatez sentimental que se le atribuye a la lírica (cf. Muecke 1982: 5-6). Este planteamiento supone una visión restrictiva $-\mathrm{y}$, en cierta medida, simplista- del fenómeno poético, pues se olvida que $e l$ poeta es un fingidor, en palabras de Pessoa, y que el personaje poético es una construcción teórica no muy alejada del paradójico comediante de Diderot. Además, la ironía y el humor, como instrumentos estéticos, desempeñan un papel decisivo en la configuración del pensamiento (pos)moderno: frente al relativismo gnoseológico y al declive de las certezas, la ironía se presenta como una respuesta refleja, ya que permite expresar el distanciamiento, la frustración de las expectativas, la oscilación entre apariencia y realidad o el cuestionamiento de las convenciones literarias. La naturaleza de la ironía incide en la modulación de la voz poética, pues contribuye a apropiarse de la anécdota, moderar la emanación sentimental y evitar un juicio moral directo (cf. Langbaum [1957] 1996: 151-196; Ballart 1994: 376-388). No obstante, la inestabilidad que conlleva la ironía no solo afecta al sujeto lírico, sino también a la construcción retórica del poema y a los pactos de lectura que se establecen entre emisor y receptor. 


\section{II. - LA IRONÍA: MOdO DE EMPLEO}

\section{II.1 La ironía en el modelo de Grice}

Desde el punto de vista pragmático se ha asumido que la explicación de la ironía planteada por Grice retoma, en cierto modo, la propuesta clásica. Según la Retórica, la ironía se define como una manera de expresar lo contrario de lo que se dice. Para Aristóteles, la ironía se vincula con las relaciones de oposición lógica, que incluyen tanto la contrariedad como la contradictoriedad. Más tarde, Cicerón y Quintiliano empiezan a cuestionarse si la ironía puede caracterizarse únicamente como decir lo contrario de lo que se dice, o si debería interpretarse como dar a entender otra cosa de la que se dice. Algunos autores han señalado que esta ampliación conceptual se debe a la traducción que realiza Cicerón del concepto de "opuesto", al que identifica exclusivamente con el término latino contrarium (cf. Marimón 2009: 18). Sin embargo, en las relaciones de oposición que contrae un término, como, por ejemplo, bueno, no solo está malo (su contrario), sino también no bueno (su contradictorio).

En el modelo de Grice ([1975] 1989), la ironía se define como una implicatura conversacional particularizada que surge por una violación ostensible de la máxima de cualidad. Se trata de un tipo de significado intencional o significado del hablante. Grice integra en el significado del hablante tanto lo que se dice como lo que se quiere decir. Lo que se dice estaría constituido, grosso modo, por las condiciones de verdad. En el ámbito de lo que se quiere decir se encuentran una serie de inferencias que, a su vez, pueden ser convencionales (debidas al significado de determinadas unidades o construcciones lingüísticas) o no convencionales. Entre estas últimas se incluirían tanto las inferencias gobernadas por el Principio de Cooperación (implicaturas conversacionales), como aquellas debidas a normas más amplias; por ejemplo, las relaciones sociales.

Para Grice, la ironía forma parte de las implicaturas conversacionales. Según el autor ([1975] 1989: 26), la comunicación es una actividad racional gobernada por un principio de naturaleza racional, el Principio de Cooperación:

Haga que su contribución a la conversación sea la exigida por el propósito, o la dirección, del intercambio comunicativo en el que se vea envuelto.

Este principio se concreta en una serie de máximas conversacionales (Grice [1975] 1989: 26-27):

-Cantidad. Está relacionada con la cantidad de información que se debe suministrar en la comunicación; y consta de dos submáximas:

a) Haga que su contribución a la conversación sea tan informativa como sea posible.

b) No haga su contribución más informativa de lo necesario.

-Cualidad. La contribución del hablante a la conversación ha de ser verdadera; de forma más específica:

a) No proporcione información falsa.

b) No proporcione información de la que no tenga evidencia suficiente. 
-Relación. La contribución del hablante a la conversación ha de ser relevante.

-Manera. La contribución del hablante a la conversación debe ser clara; en concreto:

a) Evite la oscuridad en la expresión.

b) Evite la ambigüedad.

c) Sea breve.

d) Sea ordenado.

Gracias al Principio de Cooperación y a las máximas conversacionales, se obtienen una serie de inferencias: las implicaturas conversacionales. Estas pueden generarse por el seguimiento de las máximas o por la violación de estas. Así se observa, por ejemplo, en (1) (Grice [1975] 1989: 32):

(1) A: Me he quedado sin gasolina.

B: Hay un garaje en la esquina.

El seguimiento de la máxima de relación lleva a inferir que en dicho garaje tienen gasolina, pues es la única forma de encontrar relevante el enunciado de B.

Por el contrario, pensemos en un profesor de filosofía a quien le piden un informe sobre los conocimientos en la materia de uno de sus alumnos (Grice [1975] 1989: 33). El profesor responde:

(2) Es un alumno muy educado y muy simpático. Es muy buen compañero y tiene una letra muy bonita.

De este enunciado se infiere que el alumno no tiene ni idea de filosofía; y esta inferencia, o implicatura conversacional, se ha generado por la violación ostensible de la primera submáxima de cantidad, ya que el hablante no ha dado toda la información que se le exige.

Asimismo, las implicaturas conversacionales pueden ser generalizadas o particularizadas. Las implicaturas generalizadas son aquellas que surgen siempre, a no ser que el contexto las cancele. Las implicaturas conversacionales particularizadas, por su parte, dependen de cada contexto específico. Así ocurre en el ejemplo que aparece en (3). Una fiesta está a punto de acabar, y A pregunta a B (Levinson 2000: 16-17):

(3) A: ¿Has visto a Juan?

B: Algunos invitados se han ido ya.

Del enunciado de B se infieren dos implicaturas: una generalizada (No todos los invitados se han ido); y otra particularizada, que depende de ese contexto concreto (Puede que Juan se haya ido ya). Fijémonos ahora en el mismo enunciado en un contexto diferente. En este caso, A pregunta a B:

(4) A: ¿Es muy tarde?

B: Algunos invitados se han ido ya.

En este contexto, el enunciado B permite inferir de nuevo dos implicaturas: una generalizada, que es la misma que en (3), es decir, No todos los invitados se han ido; y otra particularizada, que en este caso sería Debe de ser tarde. 
Según se ha dicho, la ironía surge como una implicatura conversacional particularizada, debida a la transgresión de la máxima de cualidad. Así, en un día lluvioso, el enunciado (5) resulta irónico, pues se ha violado la máxima de cualidad y se entiende que el hablante está expresando algo falso:

(5) Hace un día estupendo para ir de excursión.

La explicación de la ironía que plantea Grice se encuentra, no obstante, con algunos problemas. Por un lado, para algunos autores, violar una máxima supone violar también el Principio de Cooperación; por otro, existen enunciados que se calificarían como irónicos y que no consisten en decir algo falso. Así, si se sale a la calle en plena tormenta y alguien exclama:

(6) Parece que está lloviendo,

está siendo irónico, pero no transmite una información falsa (cf. Reyes 2002: 95).

Esto ha provocado que el planteamiento de Grice haya sido revisado, bien para rechazarlo o bien para modificarlo. Entre las propuestas que rechazan la explicación de Grice se encuentra la Teoría de la Relevancia (Sperber y Wilson 1986), para la que la ironía no exige procesos inferenciales especiales ni más esfuerzo interpretativo que otros tipos de comunicación, sino que puede explicarse, como cualquier acto comunicativo, por el Principio de Relevancia. En este sentido, para los relevantistas, la accesibilidad de la ironía depende del número de fuentes contextuales que contribuyan a interpretarla; funciona por acumulación o por saturación (cf. Yus 2009). Asimismo, desde esta perspectiva, el significado irónico se acaba definiendo como un uso interpretativo tácito, mediante el cual el hablante se hace eco de un pensamiento hacia el que muestra una actitud disociativa (Wilson 2006: 1730-1731)2.

Otros autores, como Attardo (2001: 112-118), han optado por partir del modelo de Grice, aunque han introducido en él algunas modificaciones. Según Attardo, la ironía implica el fracaso momentáneo del Principio de Cooperación, en la medida en que viola una máxima. No obstante, el autor considera que la ironía y el humor son formas de comunicación eficientes, por lo que el Principio de Cooperación debe restaurarse inmediatamente después de la violación de la máxima ${ }^{3}$. Attardo plantea el Principio de Interrupción Mínima (Least Disruption Principle), que consiste en reducir la suspensión del Principio de Cooperación a la unidad conversacional mínima y prolongarlo el menor tiempo posible; vincular dicha suspensión con el tópico de la conversación, y hacerlo en la dirección de las expectativas de los interlocutores. Desde este punto de vista, la ironía puede explicarse por su relevancia, ya que la violación del Principio de Cooperación no ha de hacerse de forma gratuita, sino de

2. Puede verse un repaso actualizado del análisis de la ironía para la Teoría de la Relevancia en Torres Sánchez (2009).

3. Raskin (1985) y Attardo (1994), en propuestas anteriores, han calificado la ironía y el humor como ejemplos de comunicación non bona fide. En concreto, Raskin planteó un modo de comunicación para el humor que suponía una aplicación especial del Principio de Cooperación y de las máximas. 
manera relevante; y por su condición antonímica o antifrástica, ya que está relacionada con una oposición. De forma más específica, Attardo considera que la ironía es un tipo de impropiedad; es decir, el significado irónico, como cualquier otro tipo de significado que surge de la violación de una máxima, no puede calificarse de falso, sino de inapropiado. Por ello, el autor considera imprescindible completar el Principio de Cooperación con una máxima sobre la propiedad o impropiedad de los enunciados.

Como se observa, una de las principales críticas al modelo de Grice deriva del hecho de que, para muchos autores, la violación de una máxima implica necesariamente la invalidez del Principio de Cooperación. Las implicaturas, no obstante, se pueden generar, tal como se especificó más arriba, por el seguimiento de las máximas o por la violación de estas. Igualmente, una máxima puede violarse para evitar violar otra más importante, como sucede en (7), donde se viola la máxima de cantidad (no se da toda la información requerida) para evitar violar la de cualidad (decir algo falso). Pero también puede violarse de forma ostensible, como sucede en (8):

(7) A: ¿A qué hora es la película?

B: A media tarde.

(8) Hace un día estupendo para ir de excursión [en un día de tormenta].

Sin embargo, no parece necesario hablar de suspensión del Principio de Cooperación, ni siquiera en los casos en los que la violación es flagrante, pues dicha transgresión se lleva a cabo con la aquiescencia del interlocutor, y la comunicación sigue teniendo éxito, en el sentido de que se descubren las intenciones del hablante. Esta es, en realidad, la diferencia entre ironía y mentira (cf. Haverkate 1985): en la ironía el hablante viola la máxima para que su destinatario se dé cuenta, por lo que puede entenderse como un comportamiento cooperativo; en la mentira, por el contrario, el hablante no coopera con el progreso de la comunicación, y expresa un contenido falso o lleva al destinatario a inferir implicaciones falsas sin que pueda percatarse de ello (cf. Meibauer 2005) ${ }^{4}$.

El otro problema que se desprende de la explicación de la ironía en el modelo de Grice es que no siempre los enunciados irónicos pueden entenderse como una violación de la máxima de cualidad. Esto se debe a que el significado irónico no solo puede generarse a partir de lo que se dice, sino que también puede entrar en contradicción con las implicaturas más sistemáticas de un enunciado 5 .

4. A este respecto, Chen (1990) ha planteado que el Principio de Cooperación sigue siendo válido para explicar la ironía, y únicamente necesita ser completado con algunas directrices teóricas, entre las que se encuentran: apelar al conocimiento compartido, añadir una submáxima de cualidad que dé cuenta de las presuposiciones, y desarrollar tres principios que motiven la violación de las máximas griceanas (el principio de egoísmo, el principio de cortesía y el principio de expresividad). Sin embargo, el autor no considera que estos tres principios anulen el Principio de Cooperación.

5. Este trabajo se limita a estudiar el efecto de la ironía en las implicaturas conversacionales generalizadas; con todo, la alteración que supone el significado irónico probablemente podría 


\section{II.2 La ironía en el planteamiento neogriceano}

Las propuestas neogriceanas en el estudio del significado se han centrado en las implicaturas conversacionales generalizadas; esto es, en aquellas que no dependen de un contexto específico, sino que se generan de forma sistemática a no ser que el contexto las cancele. Este carácter sistemático es precisamente lo que ha provocado que, a menudo, se conciban como parte del significado convencional de un enunciado. Los planteamientos neogriceanos se basan en la reducción del Principio de Cooperación y las máximas conversacionales a dos (Horn) o tres (Levinson) principios.

Para Horn, la cualidad es una condición irreducible, una asunción previa al intercambio comunicativo. El resto de máximas puede englobarse bajo los dos principios conversacionales que gobiernan la conversación, a partir de un equilibrio entre economía y voluntad de entendimiento: el Principio C, o Principio de Cantidad, y el Principio R, o Principio de Relación (Horn [1984] 1998).

El Principio de Cantidad combina la máxima información con la marcación formal. Insta al hablante a hacer su contribución suficiente; es decir, a dar tanta información como le sea posible. Incluye la primera máxima de cantidad y la primera y segunda de manera. Este principio es el responsable de las implicaturas escalares, contenido inferido que surge a partir de una serie de elementos ordenados a lo largo de una escala ${ }^{6}$. Según el funcionamiento de las escalas lingüísticas, el uso del miembro fuerte entraña, semánticamente, al miembro débil; y emplear el miembro débil implica, conversacionalmente, que no se puede usar el miembro fuerte. Así, según la escala

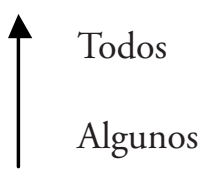

el enunciado

(9) Todos los alumnos vinieron a clase

entraña que algunos alumnos vinieron a clase. De la misma manera, de

(10) Algunos alumnos vinieron a clase

se infiere, conversacionalmente, que no todos vinieron.

En cuanto al Principio R, o Principio de Relación, combina la mínima información con la expresión formal menos marcada. Insta al hablante a hacer su contribución necesaria; es decir, a dar la información mínima para

extrapolarse también a las implicaturas convencionales.

6. Las escalas pueden ser de naturaleza lingüística (cuando la relación entre sus miembros se basa en el entrañamiento semántico) o pragmática (cuando están determinadas culturalmente o se deben a ciertas unidades lingüísticas) (Horn [1989] 2001; Fauconnier 1975; Bosque 1980; Schwenter 2001; Portolés 2004). 
sus propósitos comunicativos. Reúne las máximas de relevancia, la segunda de cantidad y la tercera y cuarta de manera. Este principio permite completar lo enunciado por el hablante. Así, puede explicar los casos de refuerzo de la negación (Horn [1989] 2001). Por ejemplo, en (11), la negación se interpreta con respecto a la proposición subordinada, de forma que puede inferirse (12):

(11) No creo que sea de fiar.

(12) Creo que no es de fiar.

Para Levinson (2000), por su parte, las máximas conversacionales se entienden como heurísticas, o formas de razonamiento por defecto. Las heurísticas, aplicadas a la comunicación lingüística, se concretan en tres principios conversacionales que reducen las máximas de Grice: el Principio de Cantidad, el Principio de Informatividad y el Principio de Manera. Levinson, al igual que Horn, cree que la cualidad es irreducible, pues constituye un requisito previo que los participantes asumen en la interacción comunicativa; asimismo, considera que la máxima de relación, o de relevancia, es capaz únicamente de generar implicaturas conversacionales particularizadas.

El Principio de Cantidad está basado en la primera submáxima de cantidad de Grice y se enuncia como (Levinson 2000: 76):

Máxima del hablante: No proporcione una información más débil que el conocimiento del mundo que posee; en concreto, seleccione el elemento más fuerte del paradigma.

Corolario del interlocutor: La información que ha ofrecido el hablante es la más fuerte que éste puede hacer.

Al igual que el de Horn, el Principio $\mathrm{C}$ es el responsable de las implicaturas escalares. Las implicaturas simples son las basadas en las escalas Horn, que hemos descrito más arriba. Así, según la escala

$$
\hat{\uparrow} \begin{aligned}
& \text { Siempre } \\
& \text { Algunas veces }
\end{aligned}
$$

el enunciado

(13) Juan va al cine algunas veces

implica, conversacionalmente, que Juan no va al cine siempre.

El Principio de Informatividad está basado en la segunda submáxima de cantidad, y Levinson (2000: 114) lo considera también un principio de refuerzo.

Máxima del hablante: Proporcione información mínima que sea suficiente para conseguir sus propósitos comunicativos.

Corolario del interlocutor: Amplíe el contenido de lo enunciado por el hablante hasta encontrar la interpretación específica.

El Principio de Informatividad permite, por ejemplo, añadir al significado meramente aditivo de la conjunción copulativa un significado temporal y causal; esto es, si se enuncia 
(14) Empezó a llover y cancelaron el partido

se infiere que primero empezó a llover y después cancelaron el partido; y también que como empezó a llover cancelaron el partido.

Asimismo, el Principio de Informatividad insta a no multiplicar los referentes; es decir, a que se establezcan relaciones de correferencia. En este sentido, se tiende a interpretar

(15) Juan llegó temprano en su coche

como que el coche era de Juan.

Finalmente, el Principio de Manera (Levinson 2000: 136-137) se enuncia como:

Máxima del hablante: Indique una situación normal mediante expresiones no marcadas.

Corolario del interlocutor: Una expresión marcada denota una situación no estereotípica.

Según este principio, si se opta por una expresión marcada como

(16) María logró parar el coche,

en vez de la expresión no marcada de (17)

(17) María paró el coche,

es porque (16) denota una situación no normal; por ejemplo, que María paró el coche tirando del freno de mano, que lo estampó contra un árbol, etc.

Las diferencias entre los modelos de Grice, Horn y Levinson ${ }^{7}$ se pueden resumir en la siguiente tabla:

\begin{tabular}{|l|l|l|}
\hline Grice (1975) & \multicolumn{1}{|c|}{ Horn (1984) } & Levinson (2000) \\
\hline $\begin{array}{l}\text { Principio de Cooperación } \\
\rightarrow \text { Máxima de Cantidad } \\
\rightarrow \text { Máxima de Cualidad } \\
\rightarrow \text { Máxima de Relación } \\
\rightarrow \text { Máxima de Manera }\end{array}$ & $\begin{array}{l}\rightarrow \text { (cualidad) } \\
\Rightarrow \text { Principio de Cantidad } \\
\Rightarrow \text { Principio de Relación }\end{array}$ & $\begin{array}{l}\rightarrow \text { (cualidad) } \\
\text { relevancia } \\
\Rightarrow \text { Principio de Cantidad } \\
\Rightarrow \text { Principio de Informatividad } \\
\Rightarrow \text { Principio de Manera }\end{array}$ \\
\hline
\end{tabular}

Los análisis de Horn y de Levinson son útiles para sistematizar el estudio de las implicaturas conversacionales generalizadas; es decir, para captar el significado de las inferencias conversacionales que surgen por defecto, a no ser

7. Más allá del número de principios conversacionales que establecen, el modelo de Horn y el de Levinson se diferencian en algunos aspectos (Traugott 2004; Horn 2006). Por ejemplo, mientras que la máxima de manera de Grice se divide en Horn entre el Principio C y el Principio $\mathrm{R}$, Levinson considera que la marcación formal es lo suficientemente importante como para constituir una heurística por sí sola (el Principio de Manera). Asimismo, ambos modelos tampoco son exactamente iguales en cuanto a su concepción del significado: la visión de Horn está más cerca de la de Grice que la última reformulación de Levinson $(1995,2000)$. Puede verse una comparación de los tres modelos en Rodríguez Rosique (2008: 46-61). 
que el contexto las cancele. Asimismo, en ambas propuestas la cualidad ocupa un lugar importante en el inicio del intercambio comunicativo: para Horn se trata de una máxima irreducible, mientras que para Levinson se asume como una condición previa, o requisito, para la interacción ${ }^{8}$.

$\mathrm{Si}$ se parte de este modelo de explicación del significado inferido, la definición de la ironía como una implicatura conversacional particularizada debida al incumplimiento de la máxima de cualidad cobra un carácter más abarcador, y puede describir un mayor número de enunciados irónicos. En efecto, la violación ostensible (con la aquiescencia del interlocutor) de la máxima de cualidad en un contexto concreto puede afectar tanto a lo dicho, como a las inferencias obtenidas de forma sistemática. En este sentido, violar el requisito de cualidad permite alterar o invertir el funcionamiento de los principios conversacionales; esto es, en una situación irónica estos principios funcionan en sentido contrario a como lo hacen habitualmente (cf. Rodríguez Rosique 2009). De esta forma, si dos amigos están comentando las desgracias que les sucedieron el año anterior y uno de ellos enuncia

(18) Fue un año buenísimo,

está legitimando el funcionamiento invertido de la escala <bueno, buenísimo>. Así, en contextos habituales, no irónicos, si alguien califica algo como buenísimo, en función de

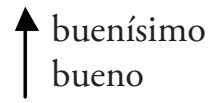

está entrañando que es bueno; igualmente, según esta escala, si se usa el miembro débil bueno se está negando conversacionalmente que el término fuerte, buenisimo, se dé. Sin embargo, en un contexto irónico, enunciar el término fuerte no entraña el término débil, sino que lo niega. La escala se ha invertido, y lo que quiere decir el hablante con (18) es que el año no fue bueno.

Las relaciones entre ironía, negación y escalaridad, y los valores «invertidos» que de ellas se desprenden, no son nada nuevo en la propuesta pragmática (cf. Bosque 1980; Horn [1989] 2001). En este sentido, Bosque habla del Principio de Negación de los Extremos para dar cuenta de la tendencia pragmática por la que negar el extremo de una escala supone la afirmación de su valor contrario. Esta tendencia se explica, en este caso, como un refuerzo pragmático de la negación, más propio del funcionamiento habitual del Principio R (en la versión de Horn), que consiste en convertir una negación proposicional en una aserción contraria, omitiendo el término medio (Horn [1989] 2001). Para que la negación dé como resultado una interpretación irónica, y no un refuerzo más o menos ritualizado, es conveniente que el elemento negado constituya el extremo de una escala -lo que se conoce como un superlativo pragmático-. Así, si se dice de alguien que No es precisamente un

8. También en el planteamiento de Grice la cualidad era una máxima más importante que el resto; de hecho, el modelo griceano legitimaba la violación de cualquiera de las otras máximas para poder respetar la de cualidad. 
adonis, mediante la negación del extremo de una escala, se afirma su contrario; es decir, se da a entender que es feo. Esta sería la diferencia entre el valor irónico (como implicatura particularizada) que puede desencadenar un superlativo pragmático y el mero refuerzo de la negación (como implicatura sistemática), que habitualmente se extrae de casos como No me gusta la sopa $>$ Me disgusta. El refuerzo de la negación suele aplicarse a términos positivos, pero que ocupan una posición intermedia en una determinada escala (cf. Horn [1989] 2001: 268-361) . No obstante, el valor irónico puede haberse convencionalizado, tal como sucede en modismos del tipo no ser moco de pavo (extremo inferior) o no haber descubierto la pólvora (extremo superior), que pueden entenderse como ser algo de importancia considerable y no haber hecho nada de especial relevancia, respectivamente (Bosque 1980: 124-132) ${ }^{10}$.

Ironía, negación y escalaridad contraen, pues, relaciones complejas que se explican si se asume que las escalas pueden proyectarse sobre el cuadrado de oposición (Horn [1989] 2001: 208):

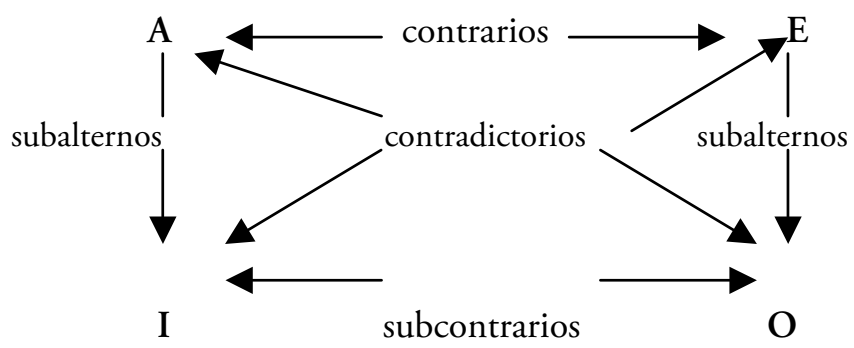

La violación de la condición inicial de cualidad puede desencadenar también el funcionamiento invertido del Principio de Informatividad enunciado por Levinson. Como se expuso más arriba, se trata de un principio de refuerzo, por el que el interlocutor ha de completar parte del significado a partir de las pistas que le ofrece el hablante. La inversión del Principio I es un recurso muy

9. Distinto, en cierto modo, sería el caso de la lítote, en la que se expresa una afirmación mediante la negación de su contrario (afirmar negando). Tradicionalmente se asume que la lítote no es exactamente equivalente a su contrapartida afirmativa, sino que el hablante la utiliza para suavizar sus aserciones, como mecanismo de protección. Para Horn ([1989] 2001: 304), en función de su «División del Trabajo Pragmático», mientras que el refuerzo de la negación se explica por su Principio R, la lítote se explica por su Principio C, puesto que las formas más largas o prolijas (las formas débiles) reflejan la indisposición del hablante para usar las más breves (o fuertes). Los casos de lítote serían formas prolijas (y débiles) que transmitirían precaución, titubeo, etc., por parte del hablante. Sin embargo, la lítote puede utilizarse también con fines irónicos, si en un contexto concreto esta sensación de protección o de titubeo por parte del hablante es solo aparente (Horn [1989] 2001: 306); es decir, si contextualmente se viola la cualidad, y lo que era sistemático ahora se ve alterado.

10. Para un estudio reciente sobre la gramaticalización de implicaturas irónicas basadas en la alteración de fenómenos escalares, puede verse Ruiz Gurillo (2009). 
explotado por los hablantes que buscan resultados humorísticos. Por ejemplo, la multiplicación de referentes es la principal responsable de los dobles sentidos:

(19) -No se puede confiar en Juan. Es muy despistado... Si robara un banco, lo atrapaban seguro.

-Si robara un banco, lo cogerían cuando intentase huir del parque con él a cuestas.

Finalmente, la transgresión ostensible del requisito de cualidad puede invertir también el Principio de Manera de Levinson. Este principio lleva a designar las situaciones habituales con expresiones no marcadas, y reserva la marcación formal para las situaciones no prototípicas. El hablante, sin embargo, puede invertir dicho principio para conseguir interpretaciones humorísticas que fomenten la complicidad entre los participantes. Se trata de un recurso muy común en lo que se ha denominado humor de registro (cf. Attardo 1994: 230253; 2001: 104-110):

(20) -No te había visto desde que acabamos el Máster. ¿A qué te dedicas ahora?

-Soy especialista en gestión domiciliaria de servicios alimenticios con vehículo de tracción motora. Trabajo en Telepizza

La explicación planteada ofrece un modelo bastante rentable para describir la ironía conservando la definición originaria de Grice. Por un lado, el significado irónico se sigue entendiendo como una implicatura conversacional particularizada, en la medida en que se genera como una violación ostensible de la máxima de cualidad. En este sentido, la importancia del contexto será fundamental, pues pondrá de manifiesto dicha infracción. Por otro lado, este análisis permite hacer un inventario de procesos habituales en la creación de enunciados irónicos, todos ellos relacionados con el funcionamiento invertido de los principios conversacionales. Finalmente, la propuesta que se ha desarrollado desemboca en una concepción prototípica del fenómeno irónico; es decir, es posible establecer fenómenos prototípicamente más irónicos que otros. Así, un enunciado del que se infiere contextualmente su negación puede considerarse un caso claro de ironía, ya que se basa en la violación contextual de la condición de cualidad; específicamente, el significado irónico es la negación de lo que se dice. No obstante, a ello puede contribuir, de manera más directa, la aparición de unidades escalares. Las escalas se proyectan sobre el cuadrado de oposición (en el que intervienen relaciones de contradicción -negación-y contrariedad -antonimia-), y su manipulación resulta especialmente rentable en contextos irónicos. Más periféricos son los recursos basados en la inversión contextual del Principio I o del Principio M, como la explotación de los dobles sentidos o el cambio inesperado de registro, respectivamente ${ }^{11}$. En estos casos,

11. A este respecto, Ruiz Gurillo (2010) considera que las marcas de la ironía (como el tono irónico, los acotadores, etc.) serían las encargadas de avisar al interlocutor de la violación de la cualidad; por el contrario, los indicadores serían los elementos sobre cuyo significado actúa la inversión irónica. Estos indicadores, a su vez, podrían dividirse en prototípicos, generalmente relacionados con algún factor que ponga en juego valores contradictorios o contrarios (como las 
el significado inferido no es estrictamente una oposición, pues no suelen verse implicadas relaciones contrarias o contradictorias; sin embargo, sí se ha generado mediante un procedimiento de inversión que lo liga a los casos más prototípicos y, discursivamente, puede desembocar en una negación, como se verá en el análisis de los poemas seleccionados ${ }^{12}$.

\section{III. - El HUMOR: ESE OSCURO OBJETO DEL ANÁLISIS}

Efectivamente, muchos de los ejemplos -y los mecanismos que los producenanalizados en el apartado anterior podrían calificarse de humorísticos. De hecho, desde bien temprano se señalaron las relaciones entre ironía y humor, y casi todos los autores que se han encargado del tema destacan la relación entre ambos fenómenos (cf., por ejemplo, Attardo 1994, 2001; Hidalgo Downing e Iglesias Recuero 2009). Hasta ahora se ha asumido que la ironía es una violación, ostensible y contextual, de la máxima de cualidad, que puede provocar -también contextualmente- el funcionamiento invertido de los principios conversacionales. Igualmente, el humor se definirá como la sustitución de un marco semántico activado por otro, lo que provoca la ruptura de las expectativas creadas en el destinatario.

La vinculación del humor con la relación de dos esquemas semánticos tiene como precedente inmediato la propuesta de Greimas (1966) en el seno de la semántica estructural. Para Greimas, el humor se basa en dos isotopías que confluyen en un mismo texto ${ }^{13}$. Una isotopía puede definirse como un conjunto de rasgos lingüísticos que apuntan al mismo significado. El paso de una isotopía a otra se produce gracias a un desencadenante que instaura un segundo ámbito de significado, y esto es lo que genera la ruptura de expectativas y el efecto humorístico.

No obstante, la reflexión más exhaustiva que se ha hecho sobre la confluencia de esquemas o marcos semánticos en relación con el humor ha sido la propuesta de Raskin (1985) y Attardo (1994; 2001), en el ámbito de su Teoría Semántica del Humor ${ }^{14}$. Desde este punto de vista, el humor se define como

escalas), y no prototípicos, entre los que se encontrarían los dobles sentidos, la desautomatización de unidades fraseológicas, el cambio de registro, etc.

12. Nótese, en este sentido, que Kalbermatten (2006) ha puesto en relación la naturaleza prototípica de la ironía con el concepto de oposición, de manera que la distinción entre ejemplares prototípicos o periféricos vendría dada por cómo se manifieste dicha oposición. Para una reflexión reciente acerca de la naturaleza prototípica de la ironía puede verse Fernández Jaén (2009).

13. Greimas no dedica ningún estudio exclusivamente al humor, y su propuesta sobre los textos humorísticos se inscribe en su teoría semántica general. En Attardo (1994) puede consultarse una revisión de la evolución del concepto greimasiano de isotopía dentro de la propia trayectoria del autor francés, y de su aplicación al fenómeno del humor.

14. La propuesta inicial es, como su propio nombre indica, de naturaleza semántica. En planteamientos posteriores se ha intentado integrar los postulados semánticos en una Teoría General del Humor Verbal, atendiendo también a otras cuestiones más generales relacionadas 
el solapamiento de dos guiones (scripts) semánticos opuestos. Los guiones equivalen a los marcos (frames) o esquemas (schemata) semánticos. Se trata de conjuntos de información basados en alguna entidad, que puede ser un objeto (real o imaginario), un hecho, una actividad, una cualidad, etc. El guión es una estructura adquirida por el hablante que incluye información sobre cómo se estructuran las entidades, qué propiedades tienen, cuáles son sus componentes, cómo se relacionan con otras entidades... Los guiones pueden estar activados directamente por un elemento léxico o pueden activarse inferencialmente. Asimismo, generan relaciones entre ellos de distinta naturaleza, como la sinonimia, antonimia, hiperonimia, etc. (Attardo 2001: 2-8). Véase el siguiente texto humorístico, con el que Raskin y Attardo ejemplifican el solapamiento de guiones, a partir de una supuesta conversación telefónica:

- ¿Está el médico en casa? -pronunciado con un susurro bronquítico por un hombre.

-No, no está - pronunciado en voz baja por la joven esposa del doctor.

-Pues voy para allá, cariño (Attardo 1994: 206).

No obstante, para Raskin y Attardo, el carácter humorístico de un texto no reside únicamente en el solapamiento de guiones; los autores consideran que los guiones solapados exhiben algún tipo de oposición. En concreto, Raskin habla de tres oposiciones en un primer nivel: real $v s$. no real; normal $v s$. anormal; posible vs. imposible. Estas oposiciones de primer nivel son susceptibles de actualizarse en otras que pueden ser propias de cada cultura y que reflejan dicotomías esenciales en la vida humana (como lo bueno frente a lo malo, la vida frente a la muerte, lo obsceno frente a lo no obsceno, etc.). Para dar cuenta de oposiciones más específicas, Raskin introduce el término de antonimia local, que define como unidades lingüísticas cuyos significados son opuestos solo en un discurso particular.

En nuestro artículo se defiende que el carácter humorístico de un texto viene dado porque el marco semántico activado es sustituido por un nuevo marco semántico. Es precisamente la sustitución lo que los convierte en marcos enfrentados, en el sentido de que son excluyentes y solo sobrevive uno de ellos en la interpretación humorística (el introducido en segundo lugar). De esta forma, no es necesario hablar de antonimias locales: el mecanismo humorístico es en sí mismo contrastivo, si se entiende el contraste en términos excluyentes. Esta perspectiva permite dar una explicación integral tanto a los casos en los que los marcos reflejen una oposición de carácter general, o culturalmente arraigada, como a aquellos en los que la oposición sea más concreta, sin necesidad de apelar a un mecanismo particular.

En definitiva, la ironía y el humor, aunque definidos de manera distinta, se presentan como extremos de un mismo continuo, el contraste. Sin embargo, mientras que la ironía se caracteriza por la violación ostensible de la máxima de

con la puesta en escena del acto comunicativo en el que se encuentra el fenómeno humorístico, como el objeto del humor o target, la situación, etc. (cf. Attardo 1994: 222-229; 2001: 22-28). 
cualidad (lo que puede desembocar bien en la negación de lo dicho, bien en la inversión de las inferencias habitualmente obtenidas de un enunciado), el humor se relaciona con la sustitución de un marco semántico por otro. Asimismo, muchos de los recursos irónicos que se desencadenan como inversión pueden también explicarse como sustitución ${ }^{15}$ :

Ironía-

Negación
CONTRASTE
Humor

Sustitución

\section{IV. - CUANDO IRONÍA RIMA CON POESÍA}

La ironía desempeña un papel relevante en la literatura comprometida después de 1939 (cf. Lechner [1968 y 1975] 2004). En el grupo del 50, diversos autores optan por la figuración irónica como un modo de distanciarse de la lírica social inmediatamente anterior, en la que la poesía se concebía aún como un arma cargada de futuro capaz de transformar activamente la realidad y de incidir en la organización del sistema político. Las llamadas a la movilización del proletariado, las sátiras antiburguesas o las solapadas consignas revolucionarias empiezan a sustituirse por una actitud más compleja y menos dogmática, lo que también se refleja en la apertura hacia ciertos temas ajenos al reducido inventario social. Aunque la ironía no excluye la toma de partido a favor de un ideario determinado, evita el riesgo del utilitarismo ideológico gracias a la autoconciencia del medio expresivo (el poema) y de las limitaciones (con)textuales que le son inherentes. La ironía se asocia con los conflictos de valores y la (mala) conciencia de clase (Gil de Biedma); los espejismos del desarrollismo urbano (Barral); las impresiones subjetivas pretéritas, enjuiciadas desde la evaluación moral del presente (Gamoneda, González); la censura de algunas costumbres o figuras representativas (Sahagún), y la reflexión sobre el propio discurso (González, Valente, Gil de Biedma).

En la obra de Ángel González, la ironía actúa como una herramienta de indagación en los contraluces de la realidad. En sus versos cobran protagonismo los contrastes dialécticos entre eternidad y destrucción, gloria y olvido, arrogancia y ruindad, belleza y frialdad (Baena 2007: 334). La aparición de la ironía es, en buena medida, consecuencia de la escisión entre los elementos antagónicos que constituyen el mundo contemporáneo, frente al que el poeta adopta una actitud de distanciada lucidez (Moreno 2004: 187). Ya en una

15. El contraste se ha analizado como un mecanismo perceptivo-cognitivo (cf. Colston y O’Brien 2000). Para los autores, la percepción de un juicio puede variar en comparación directa con algún otro con el que contraste en un parámetro determinado. Este procedimiento es claramente observable en el campo de la visión, donde los objetos pequeños pueden parecer menores cuando se observan junto a otros de mayor tamaño. Precisamente este mecanismo, basado en el efecto contrastivo, es que el se aprovecha en la ironía y en el humor, y puede ser utilizado para intensificar las funciones comunicativas de una determinada interacción. 
entrevista, Ángel González destacaba la función de la ironía como antídoto contra la impudicia experiencial y como síntoma de su concepción ambigua sobre la existencia:

La ironía ha llegado a ser para mí una manifestación de pudor, que me permite tratar determinados asuntos dolorosos sin dramatizarlos, distanciarme de ellos. En ese aspecto, es una manera respetuosa y civilizada de relacionarse con el lector, a quien no conviene abrumar con gestos excesivos. Por otra parte, la elocución irónica, en la que las cosas no son como parecen, se corresponde fielmente con mi visión del mundo radicalmente ambigua (cf. García Montero 2002a: 42).

La intención de la ironía es doble: por un lado, permite sortear la falacia sentimental y la emoción directa; por otro, sirve de soporte para la exposición de determinados contenidos que favorecen la respuesta comunicativa del lector ${ }^{16}$.

Los planteamientos anteriores se observan en la configuración de una voz irónica que se despliega a través de tres formulaciones principales: la ironía propiamente dicha, la intertextualidad y los juegos verbales (Romano 1994: 141-146). La primera estrategia supone la fractura del sentido literal y la reivindicación del relativismo antidogmático. La ironía se convierte así en el reflejo retórico de una postura moral que oscila entre el "paciente vitalismo" y las dosis de escepticismo necesarias para tolerar las declaraciones de fe en las verdades absolutas (cf. García Montero 2002b: 235). A su vez, la intertextualidad incluye la parodia y la apropiación de esquemas y tipos literarios. En este sentido, la práctica estética de Ángel González manifiesta la voluntad de invertir los patrones discursivos (la fábula didáctica, la arenga política, el documento testimonial), prevenir al lector contra una interpretación simplista y reubicar las coordenadas interpretativas en un nuevo marco textual (Benson 1981: 578579). La inversión de ideas o géneros no pretende tanto desenmascarar sus contradicciones como conferirles una nueva significación, en consonancia con la situación histórica que propone el escritor (Sánchez Torre 2005: 101-102). Finalmente, Ángel González utiliza una amplia gama de recursos estilísticos orientados a focalizar la presencia de la ironía: la deslexicalización o reproducción literal de frases hechas, los juegos de palabras, los paréntesis incisivos, la impresión de coloquialismo, los tecnicismos o cultismos, la tonalidad prosaica, el deliberado fragmentarismo o las citas manipuladas.

La mirada irónica de Ángel González se proyecta con frecuencia hacia dos territorios complementarios: los grandes conceptos universales y la realidad social, contemplada desde el prisma de la propia experiencia (cf. Payeras Grau 2009: 68-87). En el primer ámbito cabe mencionar la revisión del tema amoroso,

16. En otro fragmento de la citada entrevista, Ángel González afirma que «[d]esde otro punto de vista, la ironía estimula la imaginación del lector, lo obliga a mantenerse alerta, pues es él quien tiene que descubrir la información no enunciada que los textos irónicos proponen. Y ese descubrimiento produce sorpresa, desfamiliariza lo cotidiano, que es una de las grandes virtudes de la poesía» (cf. García Montero 2002a: 42). 
destinada a burlar los tópicos melodramáticos, rebajar el sentimentalismo e incluir aspectos relacionados con la sensualidad o el erotismo. Ejemplo de ello es «Eso era amor» (Breves acotaciones para una biografía, 1969):

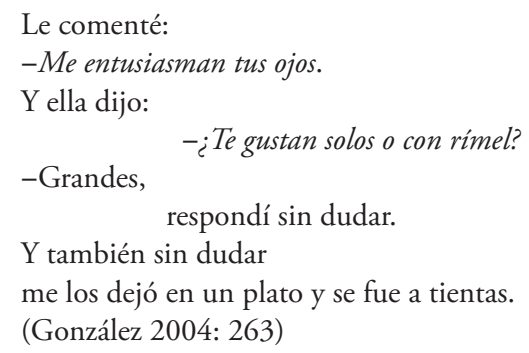

El poema arranca con una escena concreta: una pareja comparte una comida en la que se produce una declaración amorosa. El verso «-Me entusiasman tus ojos», expresado en estilo directo, actúa como desencadenante de la interpretación irónica. Dicho verso supone una inversión del Principio I basada en la multiplicación de los sentidos de "entusiasmar»: mientras que el enamorado utiliza el verbo en un sentido relacionado con el deleite estético (la belleza de la amada), su interlocutora lo interpreta en un sentido específicamente gastronómico. Prueba de ello es el verso que contiene su respuesta ( $«-\dot{\zeta}$ Te gustan solos o con rímel?»), así como el desenlace del poema («me los dejó en un plato y se fue a tientas») (Le Bigot 2005: 129). En esta dirección hay varios aspectos que avalan una interpretación irónica del texto. Por un lado, el desarrollo argumental del poema niega el título de la composición (evidentemente, eso no eva amor); por otro lado, la inversión de las expectativas conduce al distanciamiento de los tópicos al uso. No obstante, como se ha comentado anteriormente, la inversión del Principio I y del Principio M conlleva también un mecanismo sustitutivo; en realidad, el primer sentido instaura el marco amoroso, en tanto que el segundo lo reemplaza por el culinario. Esta sustitución legitima que el poema se haya entendido también en clave humorística, pues el proceso de extrañamiento que plantea es emparentable con el absurdo, la antipoesía o incluso una suerte de "surrealismo doméstico» (Salvador 2002: 289; Payeras Grau 2009: 86), que culmina con la comicidad disolvente y la desmitificación.

Por otra parte, la concepción irónica engloba varios títulos caracterizados por la dimensión social y la disidencia ideológica. Entre ellos se inscribe «Elegido por aclamación»(Grado elemental, 1962):

Sí, fue un malentendido.

Gritaron: ¡a las urnas!

y él entendió: ¡a las armas! -dijo luego.

Era pundonoroso y mató mucho.

Con pistolas, con rifles, con decretos.

Cuando envainó la espada dijo, dice:

La democracia es lo perfecto. 


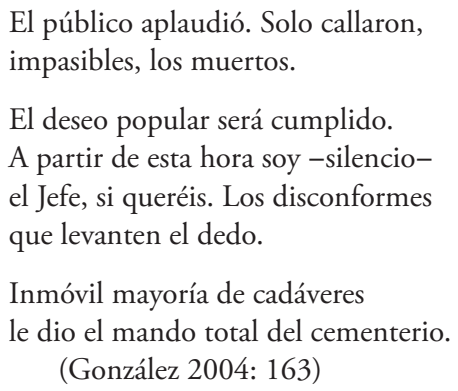

Se trata de una caricatura de la dictadura franquista; en concreto, es un poema histórico cuyo discurso contradice la historia oficial (Payeras Grau 2009: 246). En este caso, la interpretación irónica está justificada nuevamente porque el desarrollo del texto supone una negación del título. Es más, frente a lo que ocurría en el poema anterior, no solo se produce una negación proposicional, sino que esta se ve reforzada y se orienta hacia la lectura antifrástica: el antagonista no solo no es elegido por aclamación, sino que llega al poder por imposición. El sentido global se apoya en diversos recursos: la paronomasia (urnas / armas), que sugiere tácitamente la oposición democracia / dictadura; las acotaciones y precisiones prosaicas ("-dijo luego»); el desajuste entre tono y contenido («Era pundonoroso y mató mucho»); las enumeraciones (no del todo) caóticas («con pistolas, con rifles, con decretos»), y las actualizaciones temporales que suprimen la ambigüedad ("Cuando envainó la espada dijo, dice») (Prieto de Paula [1995] 2002: 252). No obstante, el humor que se filtra en algunos versos no reduce la amargura del poema. En suma, «Elegido por aclamación" puede relacionarse con la ironía trágica, que no excluye la intención catártica. De hecho, la dramatización del personaje pone en juego ciertas emociones incompatibles con la risa o con la comicidad, como la piedad o el terror.

El compromiso presente en la obra de Ángel González reaparece también en otros escritores posteriores, que pertenecen ya a la primera promoción lírica surgida con la democracia: la llamada generación de los 80 . En buena parte de estos autores, la poesía se relaciona con el tono menor y la voz en sordina. Con todo, a diferencia de lo que en ocasiones se ha planteado (cf. Cañas 1989: 52-53), no se puede afirmar que sus integrantes ignoren ni la esencial heterogeneidad del sujeto ni la centralidad de la ironía en el horizonte posmetafísico. Al contrario, la identificación de la creación artística con el simulacro está basada en la duda metódica y en la desacralización de la supuesta esencia de la poesía. Ahora la plasmación estética no siempre se corresponde con el artificio neobarroco, tal vez porque los poetas contemporáneos no pueden incurrir en la altisonancia ni permitirse excesivos alardes estilísticos: «El poeta de nuestros días parece condenado a mantener una educada modulación de voz, sin destemplanzas, y a ejercer su técnica sin alardes, procurando que la invisibilidad de esa técnica no sea menor que su eficacia» (Benítez Reyes [1996] 1998: 12) ${ }^{17}$.

17. Resuenan aquí los ecos de Auden sobre la búsqueda de la justeza de tono en el poema. 
En ese sentido ha de entenderse Vidas improbables (1995), de Felipe Benítez Reyes. Se trata de una galería de poetas y poemas apócrifos que evidencia su condición de dramatización o representación escénica. Los apócrifos de Benítez Reyes, más cercanos a los experimentos de Max Aub y a los personajes de Antonio Machado que a los heterónimos de Pessoa, ofrecen «un atractivo juego de máscaras que hace surgir la biografía y la poética de once autores imaginarios» (Jiménez Millán 2006: 104). La parodia es aquí el origen de la construcción textual, como se observa en el recorrido biográfico de «Pau Rinkel, cantor del lumpen", el último antologado en la peculiar colección. Aunque algunas composiciones de Rinkel ridiculizan los excesos del realismo sucio, la ironía adquiere un claro protagonismo más allá de la imitación, el pastiche o la parodia. Así sucede en "Ecos de sociedad», una relación de vidas cruzadas que parte de la desautomatización semántica de una unidad fraseológica ${ }^{18}$ :

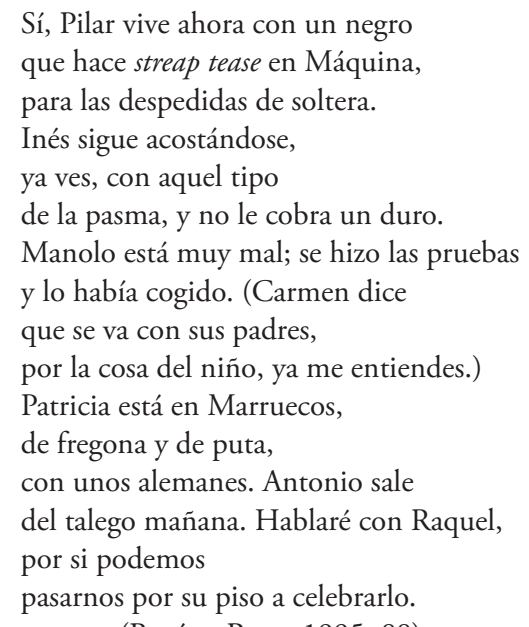

(Benítez Reyes 1995: 88)

En efecto, el carácter irónico del poema viene determinado por la inversión del Principio I, que favorece la polisemia y desencadena la lectura composicional de la unidad fraseológica «ecos de sociedad». El texto sí ofrece noticias sobre un estrato social, pero la crónica que propone el autor es más propia de la sección de sucesos que de las páginas de sociedad. De esta forma, el desarrollo del poema no solo niega el título (no son ecos de sociedad), sino que ambas lecturas (la fraseológica y la composicional) desembocan en una oposición relativa a la clase social. Frente al elitismo que convoca la interpretación fraseológica, la lectura composicional presenta un catálogo de vidas marginales provenientes del lumpemproletariado. El lector se mueve en un terreno que limita con la

No en vano, Auden consideraba que el estilo de la poesía moderna se caracterizaba por «un tono de voz íntimo, el discurso de una persona dirigiéndose a otra, o a un gran auditorio; un poeta contemporáneo que eleve su voz sonará falso» (Auden [1962] 1974: 98).

18. Para el concepto de desautomatización semántica, y su relación con la ironía, puede verse Timofeeva (2009: 212). 
categoría estética que Booth ha denominado la nauseabunda complacencia, en cuyo caso "la ironía está limitada todavía por una repugnancia sincera, que refleja un verdadero disgusto ante lo terrible que es la vida» (Booth [1974] 1989: 267).

\section{V. - De la ironía Al HUMOR: Senderos QUe SE BIFURCAN}

La poesía de la experiencia, corriente predominante en los ańos 80 y 90 , tiende a sospechar de los argumentos de la realidad. De este modo, tanto la ironía como el humor se asocian con la desconfianza en la posibilidad real del conocimiento y en la capacidad representativa del lenguaje (Iravedra 2007: 6869). La "tradición de la ironía», de estirpe anglosajona, propugna una visión antitrascendentalista del oficio, que implica al lector en las dudas sugeridas por el poeta. Por eso, ironía y humor también intervienen en la valoración moral de la realidad retratada, como demuestran las remozadas vertientes del costumbrismo (Yanke 1994: 66-67). Al mismo tiempo, los mecanismos de construcción del poema se ven reforzados por la acentuación de algunos recursos líricos tradicionales, como el uso de la rima o la actualización de los metros clásicos. En otras ocasiones, el escritor opera con «la trivialización de mitos, tópicos y motivos literarios, la conjugación de estrofas clásicas con un registro coloquial, o la aplicación de un tono elevado a un asunto prosaico» (Iravedra 2007: 74). En definitiva, se pretende establecer un diálogo lúdico o un «juego pactado» con la tradición. Así han de interpretarse aquellos artificios que contribuyen a poner de manifiesto el carácter ficticio de la obra literaria, ya sea la utilización del pastiche o el añadido de una dimensión escénica a la escritura. Los textos poéticos no se edifican directamente «sobre una experiencia de la realidad, sino sobre su representación cultural»: es decir, se sustituye lo que la poesía es por la representación de lo que fue en otro tiempo (Lanz 2007: 157). A continuación se analizan varias composiciones donde se aprecia la dimensión sustitutiva del humor, pues en ellas un marco semántico se reemplaza por otro distinto. De ese contraste surge la ruptura de las expectativas que desemboca en el efecto humorístico. A este respecto, se observará cómo funciona dicho mecanismo en tres autores contemporáneos: Víctor Botas, Luis Alberto de Cuenca y Jon Juaristi.

La poesía de Víctor Botas se adscribe al segundo tramo de la generación del 68, aunque su producción lírica se extiende desde finales de los años setenta hasta mediados de los noventa. Su obra muestra una tonalidad peculiar, fruto de la relectura de los clásicos grecolatinos. La fusión de la Historia cultural y de las historias anecdóticas e intrascendentes que le suceden al personaje poético favorece un modo de dicción que no elude ni la ironía ni la comicidad. Ironía y humor se sustentan en cuatro ingredientes que adquieren en Botas categoría cosmovisionaria: la revitalización de los géneros grecolatinos -en especial, el epigrama y la sátira-, el contraste entre los paradigmas morales de la Antigüedad y los del presente, la degradación de los tópicos literarios eternos y la ridiculización del sujeto como forma de autoparodia. De este último registro 
da prueba "Profesora de inglés», que forma parte del libro póstumo Las rosas de Babilonia (1994):

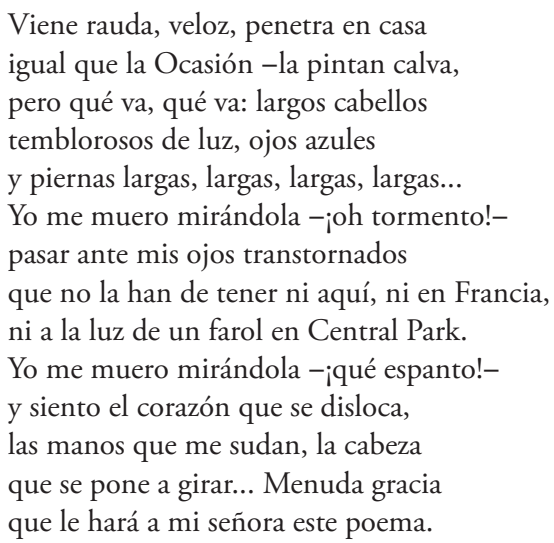

(Botas 1999: 374)

El poema presenta un tono jocoso que culmina en un desenlace epigramático. Después de una exaltación de los atributos sensuales que posee la profesora del título, y de la descripción de los efectos que ellos causan en el ánimo del poeta, se propone un regreso al territorio doméstico (Bagué Quílez 2004: 72). A lo largo del poema se activa un marco semántico que remite a las cualidades del enamorado "petrarquista»: exaltación sentimental, descripción de la belleza de la amada, identificación del amor como sufrimiento, imposibilidad de correspondencia... Sin embargo, dicho planteamiento se sustituye al final del poema por otro marco semántico que alude a un personaje de características muy distintas: un hombre corriente, que lleva una vida anodina y que, además, está casado. Este desenlace obliga a reinterpretar en clave burlesca y prosaica todos aquellos aspectos ensalzados con anterioridad.

Por su parte, «La malcasada» (El otro sueño, 1987) supone un hito en la poesía de Luis Alberto de Cuenca. Los libros La caja de plata (1985) y El otro sueño señalan una inflexión en la evolución del autor. A partir de ellos, la suntuosidad culturalista y la recreación de los mitos clásicos que habían predominado en su obra anterior se sustituyen por la fabulación de la vida cotidiana. «La malcasada» reproduce en clave humorística un tópico literario de amplia tradición y largo anclaje retórico, pues conecta con los romances de malmaridada, los ejercicios de las Academias del Barroco, la engañosa futilidad de algunas Doloras de Campoamor y ciertas composiciones del 50 (por ejemplo, "A una dama muy joven, separada», de Gil de Biedma). El tópico convoca la imagen de una mujer que no es feliz en su matrimonio. Una de sus derivaciones implica una lectura de carácter edificante; la malcasada pide consejo a un interlocutor, y este le recomienda que se cińa a los principios morales del estoicismo (resignación y asepsia espiritual):

Me dices que Juan Luis no te comprende, que solo piensa en sus computadoras y que no te hace caso por las noches. Me dices que tus hijos no te sirven, 
que solo dan problemas, que se aburren de todo y que estás harta de aguantarlos. Me dices que tus padres están viejos, que se han vuelto tacaños y egoístas y ya no eres su reina como antes.

Me dices que has cumplido los cuarenta y que no es fácil empezar de nuevo, que los únicos hombres con que tratas son colegas de Juan en IBM y no te gustan los ejecutivos. Y yo, ¿qué es lo que pinto en esta historia? ¿Qué quieres que haga yo? ¿Que mate a alguien?

¿Que dé un golpe de estado libertario?

Te quise como un loco. No lo niego.

Pero eso fue hace mucho, cuando el mundo era una reluciente madrugada que no quisiste compartir conmigo.

La nostalgia es un burdo pasatiempo.

Vuelve a ser la que fuiste. Ve a un gimnasio, píntate más, alisa tus arrugas

y ponte ropa sexy, no seas tonta, que a lo mejor Juan Luis vuelve a mimarte, y tus hijos se van a un campamento, $y$ tus padres se mueren.

(De Cuenca 1999: 138)

El poema contraviene las expectativas a las que debería ajustarse el tema escogido. Los primeros versos de «La malcasada» activan un marco semántico que concuerda con la exposición del tópico literario. En cambio, el desenlace no puede asociarse con la gravedad moral que sería esperable. En los últimos versos se activa un nuevo marco que sustituye al anterior. En ellos, el sujeto lírico hace gala de una displicencia netamente contemporánea, que se condensa en la enumeración final: "que a lo mejor Juan Luis vuelve a mimarte, / y tus hijos se van a un campamento, / y tus padres se mueren». De ahí surge el efecto humorístico. El lector se encuentra en los aledaños de la categoría que Booth denominaba la liberación cómica, entendida como una forma de acabar con las convenciones, "al servicio de un sentido gozoso de liberación de las inhibiciones» (Booth [1974] 1989: 268).

Por último, Jon Juaristi no solo es uno de los principales cultivadores del humor y de la ironía en las décadas de los 80 y 90, sino que además ha teorizado sobre sus diversas modalidades. En su artículo «El pacto realista», el autor defendía que «el deber del poeta es suscitar en quien lo lea una emoción, pero nunca tan intensa que borre los límites entre la vida y el arte» (Juaristi 1994: 25). Para ello reivindicaba el papel de la ironía como principio rector de su producción literaria. En su obra, la ironía y el humor se aplican a la dualidad amor / odio, a menudo dirigida a reproducir la indignación cívica, a truncar la anécdota sentimental o a censurar el oportunismo moral de los nuevos tiempos (Díaz de Castro 2002: 116-117). Así se observa en «Sátira primera (a Rufo)» (Los paisajes domésticos, 1992): 
Te has decidido, Rufo, a probar suerte en un certamen de provincias donde ejerzo casualmente de jurado, y encuentro razonable que me llames, al cabo de diez años de silencio, preguntando qué pasa con mi cátedra, qué fue de aquella chica pelirroja con quien ligué el ochenta en Jarandilla, cómo siguen mis viejos, si padezco todavía del hígado y si he visto a la alegre cuadrilla del Pecé. Pues bien, ya que deseas que te cuente de mí y mi circunstancia, has de saber que un punto de Alcalá me la birló, en Jodellanos gran especialista, a quien pago el café cada mańana y sustituyo volontiers los días en que marcha a simposios en San Diego, en Atlanta, Florencia o Zaragoza. Se casó con Gonzalo. El hijo de ambos va al colegio del mío, pero en vano acudo a todas las convocatorias, reuniones, funciones navideñas. La pícara me elude, y yo departo interminablemente sobre fútbol con el cretino del marido, mientras asesinan los críos una sórdida versión del Cascanueces. Bien conoces al pelma de Gonzalo. Creo, incluso, que fuiste tú quien se lo presentó. No pruebo ni una gota últimamente, después de la biopsia. Te confieso que añoro aquellos mares de vermú, aunque el agua es sanísima. Vicente, antiguo responsable de mi célula, es viceconsejero de Comercio por el Partido Popular, y, claro, se mueve en otros medios. Otra gente parece preferir ahora Vicente. Mis padres van tirando. Cree, Rufo, que nada tengo contra ti. Al contrario, te recuerdo con franca simpatía. Es cierto que arruinaste mi mecano, que me rompiste el cambio de la bici, que le contaste a mi primera novia lo mío con tu prima, la Piesplanos. Eras algo indiscreto, pero todos tenemos unos cuantos defectillos. Veré qué puedo hacer. No te prometo nada: somos catorce y, para colmo, corre el rumor de que Juan Luis Panero. 
En el poema, el Rufo del título, apelando a una antigua amistad con el autor, le pide recomendación en un certamen en el que este participa como jurado. Después de recordar las horas pasadas en la infancia y juventud con el citado Rufo, Juaristi decanta el poema hacia un desenlace en el que insinúa la dificultad de que su amigo se haga con el galardón al que aspira.

$\mathrm{Si}$ «Profesora de inglés» era un ejemplo prototípico de texto humorístico y «La malcasada» sustentaba su comicidad en la relectura de un tópico literario, «Sátira primera (a Rufo)» basa su efectividad en la vulneración de un género fronterizo entre la ironía y el humor: la sátira literaria. El poema consigue su efecto humorístico mediante la sustitución de planos semánticos excluyentes. El desarrollo concuerda con algunos aspectos propios de la sátira: la existencia de una víctima y la exposición de una conducta moral reprobable. Sin embargo, los últimos versos activan un marco semántico distinto: la víctima resulta ser un "pobre diablo», que no merece los esfuerzos del autor, y el sujeto poético tampoco se corresponde con el moralista habitual, ya que es un personaje desencantado, un relativista incapaz de proponer alternativas éticas a su interlocutor. Esta sustitución lleva a cuestionar el carácter satírico del poema, pues no se ofrece un paradigma moral orientado a reemplazar los valores satirizados, ni se esboza la función principal de la sátira desde su configuración clásica: corregir las costumbres ${ }^{19}$. En sentido estricto, la «Sátira» de Juaristi no podría considerarse un texto satírico, sino más bien su reverso: la parodia de una sátira, que dialoga intertextualmente con el género al que alude el título, pero que cancela su finalidad. Por todo ello, cabría plantearse la naturaleza irónica del texto: en realidad, su desarrollo acaba por negar el título. La diferencia con respecto a los poemas irónicos analizados en el apartado anterior reside en el alcance de la negación, que aquí no solo tiene un valor proposicional, sino que, además, supone la inversión de un género literario.

\section{VI. - CONCLUSIÓN: TAN SOLO BUSCO CÓMPLICES QUE SEPAN DE QUÉ HABLO}

En definitiva, el análisis de los poemas seleccionados refuerza la hipótesis planteada en este artículo. Ironía y humor son dos mecanismos contrastivos que representan los extremos de un continuo, si bien sus definiciones específicas se ven reflejadas en su respectivo funcionamiento dentro del discurso estético. En los poemas relacionados con el fenómeno de la ironía, el significado del texto se consigue mediante la negación catafórica del título. En cambio, en los poemas relacionados con el humor, son los desenlaces climáticos o anticlimáticos los que desencadenan el efecto humorístico. La contundencia del último verso o su distensión emotiva obligan a sustituir el marco semántico previamente

19. Según Ballart, «la principal diferencia que aleja las creaciones del autor satírico de las del ironista es que aquellas están construidas sobre la falsilla de un programa moral inequívoco, de una obvia intención reformadora» (Ballart 1994: 418). 
activado por otro que rompe las expectativas $\operatorname{creadas}^{20}$. La diferencia esencial entre un mecanismo y otro se representa en las siguientes figuras:

Ironía: negación

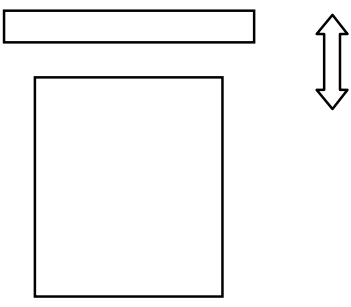

Humor: sustitución

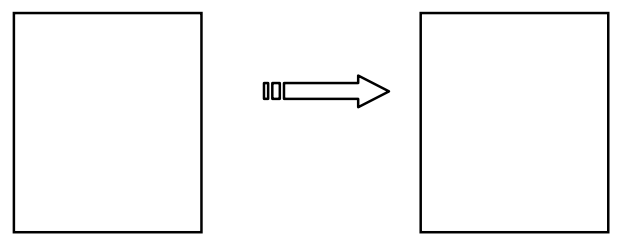

Desde un punto de vista general, la ironía y el humor se inscriben en el ámbito de un realismo posmoderno (cf. Oleza 1996), que intenta compatibilizar los rasgos originales de la posmodernidad con las modalidades del discurso realista. Este planteamiento supone un retorno al sujeto y una progresiva desacralización de los tópicos románticos acerca de la literatura. El realismo posmoderno se considera una estrategia orientada a conciliar la creatividad y la realidad, el lenguaje y su referente, la belleza artística y la vida cotidiana (Bagué Quílez 2006: 31-34).

Dentro del realismo posmoderno se perfilan dos aspectos que resultan fundamentales para entender el papel que juegan la ironía y el humor: la existencia de un pacto autobiográfico entre emisor y destinatario (Lejeune [1975] 1994) y la búsqueda de un efecto de complicidad entre autor y lector. El pacto autobiográfico proporciona la pauta de lectura de los textos, pues establece un espacio de ficción compartido que se sustenta en una ilusión de realidad. A su vez, la complicidad se concibe como una instancia comunicativa para cuya culminación es necesario que se produzca una oscilación entre tonalidad crítica y voluntad comunicativa.

La ironía y el humor son mecanismos de distanciamiento emotivo, pues canalizan las efusiones sentimentales, rebajan las afirmaciones teñidas de excesivo lirismo y evitan la altisonancia retórica. Además, la distancia que imponen la ironía y el humor favorece la autoconciencia y la crítica a los productos

20. Desde la perspectiva pragmática, la vinculación de la ironía con la negación ha sido también planteada por algunos autores, como Giora (1995), para quien el fenómeno irónico consiste en una negación indirecta; es decir, una negación sin marcas negativas explícitas. Por otra parte, los textos humorísticos analizados responden a la misma estructura canónica que Attardo $(1994,2001)$ ha planteado para los chistes tradicionales. 
artísticos banales o kitsch (Bozal 1999: 98-101). De igual manera, el ironista y el humorista ponen en tela de juicio los argumentos de la realidad mediante el desmontaje de los tópicos que la configuran. Frente a las cosmovisiones cerradas, los valores absolutos y los metarrelatos explicativos (Lyotard [1979] 1987), la ironía y el humor tienden a relativizar las certezas, atenuar el énfasis en las creencias y matizar las propias percepciones (Vattimo [1985] 1994; Vattimo y Rovatti [1983] 2000).

Sin embargo, ambos procedimientos no pueden caracterizarse únicamente en términos de distanciamiento, pues también pretenden conseguir la adhesión del lector, hablarle en un tono de voz confidencial e intercambiar con él ideas y convicciones (Iravedra 2007: 70-71, Yanke 1994: 63-64). Precisamente, la complicidad se encuentra en la intersección entre distancia y proximidad: su espacio está a medio camino entre la autonegación posmoderna (Hernández Sánchez 2002: 80-81) y la cercanía afectiva y humana. Ese movimiento de ida y vuelta contribuye a una "catarsis irónica» (Juaristi 1994: 26) que reivindica el papel liberador consagrado a la ironía y al humor desde el Romanticismo. En última instancia, el autor contemporáneo no tiene más remedio que suscribir uno de los propósitos que Marzal expresaba en "Las buenas intenciones»: «tan solo busco cómplices que sepan de qué hablo».

\section{BiBLIOGRAFÍA}

Attardo Salvatore, Linguistic theories of humor, Berlín / Nueva York, Mouton de Gruyter, 1994.

- Humorous texts: A semantic and pragmatic analysis, Berlín / Nueva York, Mouton de Gruyter, 2001.

Auden W. H. (1962), La mano del teñidor y otros ensayos, Barcelona, Barral, 1974.

Baena Enrique, Metáforas del compromiso (Configuraciones de la poética actual y creación de Ángel González), Madrid, Cátedra, 2007.

Bagué Quílez Luis, La poesía de Victor Botas. Una relectura de los clásicos grecolatinos, Gijón, Llibros del Pexe, 1994.

- Poesía en pie de paz. Modos del compromiso hacia el tercer milenio, Valencia, Pre-Textos, 2006.

Ballart Pere, Eironeia. La figuración irónica en el discurso literario moderno, Barcelona, Quaderns Crema, 1994.

Benítez Reyes Felipe, Vidas improbables, Madrid, Visor, 1995.

- (1996), "La certeza de las dudas (Tres ensayos sobre la Poesía)», en Paraísos y mundos (Poesía reunida 1979-1991 y otros poemas), Madrid, Hiperión, 1998, pp. 7-30.

Benson Douglas K., «La ironía, la función del hablante y la experiencia del lector en la poesía de Ángel González», 1981, Hispania, 64, pp. 570-581.

Booth Wayne (1974), Retórica de la ironía, Madrid, Taurus, 1989.

Bosque Ignacio, Sobre la negación, Madrid, Cátedra, 1980.

Botas Víctor, Poesía completa, Gijón, Llibros del Pexe, 1999.

Bozal Valeriano, Necesidad de la ironía, Madrid, Visor, 1999.

Cañas Dionisio, «El sujeto poético posmoderno», Insula, 1989, 512-513, pp. 52-53

Chen Rong, Verbal irony as conversational implicature, Ball State University (Indiana), 1990 (Tesis Doctoral).

Colston Herbert L. y Jennifer O’Brien, "Contrast and pragmatics in figurative language: Anything understatement can do, irony can do better», 2000, Journal of Pragmatics, 32, pp. 1557-1583. 
De Cuenca Luis Alberto, Los mundos y los días. Poesía 1972-1998, Madrid, Visor, 1999.

Díaz de Castro Francisco, Vidas pensadas. Poetas en el fin de siglo, Sevilla, Renacimiento, 2002.

Fauconnier Gilles, "Pragmatic scales and logical structures», Linguistic Inquiry, 1975, VI, 3, pp. 353375.

Fernández Jaén Jorge, «Ironía y lingüística cognitiva», en Leonor Ruiz Gurillo y Xose A. Padilla García (eds.), Dime cómo ironizas y te diré quién eres. Una aproximación pragmática a la ironía, Frankfurt am Main, Peter Lang, 2009, pp. 391-422.

García Montero Luis, «Conversación con Ángel González», en VV.AA, Ángel González. Tiempo inseguro, Málaga, Litoral, 2002, pp. 15-27.

— «Historia y experiencia en la poesía de Ángel González», en VV.AA., Ángel González. Tiempo inseguro, Málaga, Litoral, 2002, pp. 230-239.

Giora Rachel, «On irony and negation», Discourse Processes, 1995, 19, pp. 239-264.

González Ángel, Palabra sobre palabra. Obra completa (1956-2001), Barcelona, Seix Barral, 2004.

Greimas Algirdas J., Sémantique structurale: recherche de méthode, París, Larousse, 1966.

Grice H. Paul (1975), «Meaning», en Studies in the way of words, Cambridge / Londres, Harvard University Press, 1989, pp. 213-223.

Haverkate Henk, «La ironía verbal: un análisis pragmalingüístico», Revista Española de Lingüistica, 1985, 15, 2, pp. 343-391.

Hernández Sánchez Domingo, La ironía estética. Estética romántica y arte moderno, Salamanca, Universidad de Salamanca, 2002.

Hidalgo Downing Raquel y Silvia Iglesias Recuero, «Humor e ironía: una relación compleja», en Leonor Ruiz Gurillo y Xose A. Padilla García (eds.), Dime cómo ironizas [...], Frankfurt am Main, Peter Lang, 2009, pp. 423-455.

Horn Laurence R. (1984), "Toward a new taxonomy for pragmatic inference: Q-based and R-based Implicature», en Asa Kasher (ed.), Pragmatics IV, Londres / Nueva York, Routledge, 1998, pp. 383-418.

Horn Laurence R. (1989), A natural history of negation, Stanford, CSLI Publications, 2001.

— «The border wars: a neo-Gricean perspective», en Ken Turner y Klaus von Heusinger (eds.), Where semantics meets pragmatics, Ámsterdam, Elsevier, 2006, pp. 21-48.

Iravedra Araceli, «Palabras de familia gastadas tibiamente (Notas para la historia de un paradigma lírico)», en Araceli Iravedra (ed.), Poesía de la experiencia, Madrid, Visor, 2007, pp. 7-175.

Jiménez Millán Antonio, Poesía hispánica peninsular (1980-2005), Sevilla, Renacimiento, 2006. Juaristi Jon, «El pacto realista», Insula, 1994, 565, pp. 25-26.

- Poesía reunida (1985-1999), Madrid, Visor, 2000.

Kalbermatten María Isabel, Verbal irony as a prototype category in Spanish: A discoursive analysis, Minnesota, Universidad de Minnesota, 2006.

Langbaum Robert (1957), La poesía de la experiencia. El monólogo dramático en la tradición literaria moderna, Granada, Comares, 1996.

Lanz Juan José, La poesía durante la Transición y la generación de la democracia, Madrid, Devenir, 2007.

Le Bigot Claude, «La forma breve en la obra poética de Ángel González», Zurgai, 2005, pp. 122130.

Lechner Jan (1968 y 1975), El compromiso en la poesía española del siglo XX, Alicante, Universidad de Alicante, 2004.

Lejeune Philippe (1975), El pacto autobiográfico y otros estudios, Madrid, Megazul / Endymión, 1994.

Levinson Stephen C., "Three levels of meaning», en Frank R. Palmer (ed.), Grammar and meaning, Cambridge, Cambridge University Press, 1995, pp. 90-115.

- Presumptive meaning. The theory of generalized conversational implicature. Cambridge / Londres, The MIT Press, 2000.

Lyotard Jean-François (1979), La condición postmoderna, Madrid, Cátedra, 1987. 
Marimón Carmen, «La retórica», en Leonor Ruiz Gurillo y Xose A. Padilla García (eds.), Dime cómo ironizas [...], Frankfurt am Main, Peter Lang, 2009, pp. 13-44.

Meibauer Jörg, «Lying and false implicating», Journal of Pragmatics, 2005, 37, pp. 1373-1399.

Moreno Antonio, «La poesía de Ángel González, una viva historia», en Los espejos del domingo y otras lecturas de poesía, Sevilla, Renacimiento, 2004, pp. 175-191.

Muecke Douglas C., Irony and the ironic, Londres, Methuen, 1982.

Oleza Joan, «Un realismo posmoderno», Insula, 1996, 589-590, pp. 39-42.

Payeras Grau María, El sueño de la realidad. Poesía y poética de Ángel González, Santa Cruz de Tenerife, La Página, 2009.

Portolés José, Pragmática para hispanistas, Madrid, Síntesis, 2004.

Prieto de Paula Ángel L. (1995), Poetas españoles de los cincuenta. Estudio y antología, Salamanca, Almar, 2002.

Raskin Victor, Semantic mechanisms of humor, Dordrecht / Boston / Lancaster, D. Reidel, 1985.

Reyes Graciela, Metapragmática. Lenguaje sobre lenguaje, ficciones, figuras, Valladolid, Universidad de Valladolid, 2002.

Rodríguez Rosique Susana, Pragmática y gramática. Condicionales concesivas en español, Frankfurt am Main, Peter Lang, 2008.

Rodríguez Rosique Susana, "Una propuesta neogriceana», en Leonor Ruiz Gurillo y Xose A. Padilla García (eds.), Dime cómo ironizas [...], Frankfurt am Main, Peter Lang, 2009, pp. 109-132.

Romano Marcela, "Ángel González, la voz en desconcierto», en Laura Scarano, Marcela Romano y Marta Ferrari, La voz diseminada. Hacia una teoría del sujeto en la poesía española, Buenos Aires, Biblos, 1994, pp. 127-146.

Ruiz Gurillo Leonor, "La gramaticalización de las unidades fraseológicas irónicas», en Leonor Ruiz Gurillo y Xose A. Padilla García (eds.), Dime cómo ironizas [...], Frankfurt am Main, Peter Lang, 2009, pp. 371-390.

Ruiz Gurillo Leonor, «Para una aproximación neogriceana a la ironía en español», Revista Española de Lingüistica, 2010, 40, 2, pp. 95-124.

Salvador Álvaro, «La palabra precisa de Ángel González», en VV.AA, Ángel González. Tiempo inseguro, Málaga, Litoral, 2002, pp. 288-292.

Sánchez Torre Leopoldo, «La inversión de los géneros discursivos en Grado elemental, de Ángel González», Zurgai, 2005, pp. 98-103.

Schwenter Scott, «Additive particles and the construction of context», Quaderns de Filologia. Estudis Lingüistics, 2001, VI, pp. 245-262.

Sperber Dan y Deirdre Wilson, Relevance. Communication and cognition, Oxford, Blackwell, 1986.

Timofeeva Larissa, «Las unidades fraseológicas», en Leonor Ruiz Gurillo y Xose A. Padilla García (eds.), Dime cómo ironizas [...], Frankfurt am Main, Peter Lang, 2009, pp. 193-217.

Torres Sánchez María Ángeles, «La relevancia», en Leonor Ruiz Gurillo y Xose A. Padilla García (eds.), Dime cómo ironizas [...], Frankfurt am Main, Peter Lang, pp. 65-87.

Traugott Elizabeth C., "A critique of Levinson's view of Q- and M-inferences in historical pragmatics", Journal of Historical Pragmatics, 2004, 5, 1, pp. 1-25.

Vattimo Gianni (1985), El fin de la modernidad. Nibilismo y hermenéutica en la cultura posmoderna, Barcelona, Gedisa, 1994.

Vattimo Gianni y Pier Aldo Rovatti (1983) (eds.), El pensamiento débil, Madrid, Cátedra, 2000.

Wilson Deirdre, "The pragmatics of verbal irony: echo or pretence?», Lingua, 2006, 116, pp. 1722-1743.

Yanke Germán, «La figuración irónica», Scriptura, 1994, 10, pp. 53-67.

Yus Francisco, «Saturación contextual en la comprensión de la ironía», en Leonor Ruiz Gurillo y Xose A. Padilla García (eds.), Dime cómo ironizas [...], Frankfurt am Main, Peter Lang, 2009, pp. 309-345. 